\title{
Influence of occupational diving upon the nervous system: an epidemiological study
}

\author{
K Todnem, H Nyland, B K Kambestad, J A Aarli
}

\begin{abstract}
Neurological signs and symptoms were recorded from 156 air and saturation divers and 100 controls. Fifty one $(33 \%)$ of the divers had had symptoms from the central nervous system during decompression. Also, $22(14 \%)$ had been unconscious while diving. In total $79(51 \%)$ had had decompression sickness (DCS). Twelve $(8 \%)$ of the divers and no controls had had specific neurological symptoms (vision disturbances, vertigo, reduced skin sensitivity) in non-diving situations, and six $(4 \%)$ of the divers (no controls) had had episodes of cerebral dysfunction (seizures, transient cerebral ischaemia, transient amnesia). The divers had significantly more general symptoms from the nervous system and more abnormal neurological findings than the controls. The most prominent symptoms were difficulties in concentration and problems with long and short term memory. The most prominent abnormal findings in the divers were compatible with dysfunction in the distal spinal cord or nerve roots, and polyneuropathy. The general neurological symptoms and findings were independently significantly correlated with diving exposure, prevalence of DCS, and age.
\end{abstract}

Diving is a unique occupation; every time a diver surfaces from a depth of more than 10 metres of seawater (msw), he must follow a decompression procedure to avoid decompression sickness (DCS); DCS has been classified as type 1 (DCS 1), which includes musculoskeletal pain, and type 2 (DCS 2), which includes symptoms from the nervous system. ${ }^{1}$ Divers are subject to increasing hyperbaric pressure on all organ systems; they are influenced by increased pressure of nitrogen in air diving, by inert gases in

Norwegian Underwater Technology Centre and Department of Neurology, University of Bergen, Norway

K Todnem, H Nyland, B K Kambestad, J A Aarli saturation diving, increased pressure of oxygen, and also to possible toxic agents in the diving environment. All of these factors may present a hazard to the divers.

Rozsahegyi found that $75 \%$ of caisson workers with DCS 2 had residual neurological signs or symptoms. ${ }^{2}$ Dolmierski et al found that $30 \%$ of a group of air divers had abnormal neurological findings, although only half of them had had DCS. ${ }^{3}$ Værnes et al found that $20 \%$ of saturation divers had neuropsychological deficits after a mean of 3.4 years of diving. ${ }^{4}$ The present paper appears to be the first report of neurological symptoms and findings by neurological examination in a non-selected group of commercial saturation divers. The study was part of the national research programme on long term health effects of diving.

\section{Methods \\ DIVERS}

One hundred and fifty six male commercial divers were examined. Mean age of the divers was 33.6 (range 21-49) years. The only inclusion criterion for the divers was a record as a commercial diver for at least one year. One hundred and forty three had a permanent address in Norway, and 13 were living abroad but worked in Norway. One hundred and six Norwegian divers employed by diving companies were invited by a personal letter to participate and some of them were contacted by telephone. The secondary response rate was $72 \%$ (76 divers). The rest were invited by advertising. At that time there were 294 Norwegian divers with a diving bell certificate. At the time of examination $31(20 \%)$ divers had stopped diving. Six had lost their diver's licence because of neurological problems, but all of them worked. The rest had moved on to other jobs. None of the divers were examined in a state of acute DCS.

\section{EXPOSURE TO DIVING AND EXPOSURE INDICES}

One hundred and thirty three divers had performed both air and saturation diving, whereas 23 had performed only air diving. Forty had dived to greater depths than 180 metres of seawater (msw). The greatest depth was $500 \mathrm{msw}$. The mean diving experience was $9 \cdot 7$ (range 1-29) years of diving and the mean air diving experience was 627 (range 10- 
5220 ) days. The mean saturation experience was 288 (range 14-804) days in saturation.

Exposure indices (total number of days) for air diving and saturation diving were calculated for each diver. Total exposure to diving was calculated from the sum of the indices. Because the exposure was log normally distributed, logarithmic transformation was used in the analysis of risk factors.

\section{CONTROLS}

One hundred male workers served as control subjects. The mean age was 34 (range 22-48). The inclusion for the control subjects were that they were aged between 20 and 50, that they had never practised diving, and that they had health standards comparable to having a diving certificate. The control group consisted of offshore personnel and police officers. Some 170 offshore workers were invited to participate by advertising. Fifty three responded and were examined. The rest of the control group was recruited from advertising among 270 policemen. The first 50 responders were examined.

\section{EDUCATION}

Four per cent of the controls and $18 \cdot 6^{\circ}{ }_{0}$ of the divers had nine years of school; $52.0^{\circ}{ }_{0}$ of the controls and $56.4^{\circ}{ }_{0}$ of the divers had 12 years; and $44^{\circ}{ }_{0}$ of the controls and $25^{\circ}{ }_{0}$ of the divers had more than 12 years of education. The controls had significantly more years of formal education than the divers $\left(\mathrm{p}=0.0002\right.$, Pearson's $\chi^{2}$ test $)$.

\section{SMOKING HABITS}

Fifty five $\left(35^{\circ}{ }_{0}\right)$ of the divers and $38\left(38^{\circ}{ }_{0}\right)$ of the controls smoked cigarettes; The difference was not significant $\left(\mathrm{p}=0.656\right.$, Pearson $\chi^{2}$ test).

\section{USE OF ALCOHOL}

This was graded from 1 (low) to 4 (high) in a combined measure of how frequently the subjects drank ethanol and the amount. When the divers were grouped according to use of alcohol, the mean figures were as follows, with controls in parentheses: Grade $1,7 \cdot 1(13 \cdot 0)$; grade $2: 62 \cdot 2(74 \cdot 0)$; grade 3: $26 \cdot 9(13 \cdot 0)$; grade $4: 3 \cdot 8(0)$. The divers drank significantly more alcohol than the controls $\left(p=0.005\right.$, Pearson's $\chi^{2}$ test).

\section{ETHICAL CONSIDERATIONS}

Permission to establish a register for divers and controls was given by The Data Inspectorate. Both divers and controls were informed that their medical data were available to themselves and kept in special files, and that the data would be used for scientific purposes only unless they were personally informed.

INTERVIEW

A standardised interview by one neurologist focused on education, medical history, complications in connection with diving, symptoms from the central nervous system (CNS), the peripheral nervous system (PNS), the autonomic nervous system (ANS), and use of tobacco and alcohol.

The CNS symptoms were defined as problems with short and long term memory, difficulties of concentration, lability of mood, fatigue, problems of work management, headache, and dizziness. Problems of short term memory were defined as inability to remember appointments, problems with control of personal belongings, and extensive use of memory aids. Problems of long term memory were defined as poor memory for written material and earlier events. The questions were answered with "yes" or "no". In cases of "yes" the subjects' own opinion was that they had a real problem, or that the relevant function had decreased significantly over the last five years. Neuropsychological testing was not included in this investigation.

The PNS symptoms comprised paraesthesia and pain in feet and hands and muscular weakness.

The ANS symptoms comprised cardiac palpitation, excessive sweating, chest oppression, sexual dysfunction, orthostatic hypotension, and episodes with diarrhoea and constipation. Each of these symptoms may have had causes other than dysfunction of the ANS. This was controlled for by additional questions. If other relevant causes were found, the symptom was not attributed to the ANS. Symptoms from the PNS and ANS were graded from 1 ("I never have this symptom") to 4 ("I have this symptom every day").

\section{NEUROLOGICAL EXAMINATION}

The neurological examination was performed by a neurologist according to a previously defined protocol. ${ }^{5}$ The findings were classified as normal or abnormal. Muscle stretch reflexes were graded as symmetric, asymmetric, or increased, and abdominal muscle reflexes as normal, asymmetric, or absent. Plantar reflexes were graded as symmetric, asymmetric, or inverted (Babinski positive).

\section{Statistical methods}

Pearson's $\chi^{2}$ test and Fisher's exact two tailed test were applied for comparison between groups of categorical variables. The relation between risk factors and the different test results were evaluated by multiple linear regression analysis. The covariation between risk factors was tested with a stepwise procedure. Small $p$ values indicate that the risk factor should be included as an explanatory factor. The stepwise procedure includes in turn the risk factor with the lowest $p$ value and thus the strongest influence on the tested variable. ${ }^{6}$ 
Table 1 Medical history in divers and controls

\begin{tabular}{|c|c|c|c|}
\hline & $\begin{array}{l}\text { Divers } \\
(n=156) \\
\text { No }\left({ }^{o}{ }_{o}\right)\end{array}$ & $\begin{array}{l}\text { Controls } \\
(n=100) \\
N o\left(\begin{array}{l}0 \\
o\end{array}\right)\end{array}$ & p Value \\
\hline \multicolumn{4}{|l|}{ Episodes of cerebral } \\
\hline Neurological symptoms + & $12(8)$ & $0(0)$ & $0.0047^{\star}$ \\
\hline Cerebral concussion & $60(39)$ & $33(33)$ & 0.451 \\
\hline Viral meningitis & $2(1)$ & $1(1)$ & $1 \cdot 0$ \\
\hline Other viral infections $§$ & $111(71)$ & $42(42)$ & $0.0001^{\star}$ \\
\hline Bronchitis and/or pneumonia & $33(21)$ & $37(37)$ & $0.009^{\star}$ \\
\hline Allergy & $52(33)$ & $39(39)$ & 0.355 \\
\hline Fractures of extremities & $78(50)$ & $49(49)$ & $1 \cdot 0$ \\
\hline Lumboischialgia & $66(42)$ & $36(36)$ & 0.382 \\
\hline Gastritis or peptic ulcer & $19(12)$ & $14(14)$ & 0.795 \\
\hline Bowel disorder & $8(5)$ & $4(4)$ & $0 \cdot 770$ \\
\hline Treated anxiety & $2(1)$ & $4(4)$ & $0 \cdot 213$ \\
\hline Treated depression & $10(6)$ & $3(3)$ & $0 \cdot 260$ \\
\hline
\end{tabular}

*Significant difference between divers and controls (Pearson's $\chi^{2}$ test).

†Three divers with seizures, two with episodes of transient cerebral ischaemia, and one with an episode of transient global amnesia.

†Four divers with episodes of vision disturbances, four with vertigo, and four with reduced skin sensitivity.

§once or more each year.

\section{Results}

MEDICAL HISTORY

Table 1 presents the medical histories of divers and controls. Episodic neurological symptoms in nondiving situations had occurred in 12 divers and in none of the controls. Ten more divers had lasting neurological symptoms, six after treated DCS and the others of unknown cause.

Six divers had been referred to departments of neurology because of acute episodes of cerebral dysfunction. Four of them had dived to a depth greater than $180 \mathrm{msw}$, and they had had episodes with seizures, transitory cerebral ischaemia, and transient amnesia (reported in detail elsewhere). The two divers who had never performed deep diving had had episodes compatible with seizures and transitory cerebral ischaemia. Cerebral concussion, defined as unconsciousness after head injury, was not significantly different in the two groups.

Viral infections, defined as episodes with fever, common cold symptoms, and generalised malaise, occurred significantly more often in divers whereas
Table 2 Complications of divers in connection with diving

\begin{tabular}{|c|c|c|c|c|}
\hline & \multicolumn{4}{|c|}{ No of episodes for each diver } \\
\hline & 1 & $2-5$ & $>5$ & $\operatorname{Sum}\left({ }^{\circ}\right)$ \\
\hline $\begin{array}{l}\text { DCS 2; brain symptoms } \\
\text { DCS } 2 \text {; spinal cord }\end{array}$ & 32 & 6 & 3 & $41(26)$ \\
\hline $\begin{array}{l}\text { symptoms } \\
\text { Unconsciousness: }\end{array}$ & 12 & 3 & 2 & $17(11)$ \\
\hline $\begin{array}{l}\text { not DCS } \\
\text { DCS } 1 \& 2 \\
\text { Skin bend/lymphoedema } \\
\text { Lung complications }\end{array}$ & $\begin{array}{r}18 \\
41 \\
22 \\
2\end{array}$ & $\begin{array}{r}4 \\
33 \\
15 \\
3\end{array}$ & $\begin{array}{r}0 \\
5 \\
20 \\
4\end{array}$ & $\begin{array}{c}22(14) \\
79(51) \\
57(37) \\
9(6)\end{array}$ \\
\hline
\end{tabular}

pulmonary infections were reported significantly more often in the controls. Two previous divers and one control subject had mild hypertension, one previous diver had chest angina, one other previous diver had diabetes, and one control subject had had cancer.

\section{COMPLICATIONS ASSOCIATED WITH DIVING}

Altogether 51 (33\%) divers had experienced symptoms from the CNS, and $79(51 \%)$ had had DCS 1 or 2 or both (table 2).

\section{SYMPTOMS FROM THE CNS, PNS, AND ANS}

Table 3 presents the neurological symptoms for divers and controls. A mean score for positive symptoms was calculated for each subject. The score ranged from 0 for subjects with no symptoms to 100 for those with positive symptoms in all variables. The divers had significantly more symptoms from the CNS than the controls. Problems of concentration and short and long term memory prevailed. Impaired concentration score was 22.4 for the divers and 4.0 for controls ( $p<0.0001$, Fisher's exact two tailed test). Impaired short term memory score was 27.6 for the divers and 7.0 for controls $(p<0.0001)$. Impaired long term memory score was 13.5 for the divers, and 4.0 for controls $(p=0.0162)$.

The divers had significantly more symptoms from the PNS than controls with paraesthesia in feet and hands as the most prevailing symptom. The paraesthesia score was 11.8 for the divers and 4.0 for controls $(p=0.0126)$.

Table 3 Neurological symptoms in divers and controls

\begin{tabular}{|c|c|c|c|c|c|c|}
\hline & & \multicolumn{5}{|c|}{ Abnormal neurological symptoms in per cent of variables } \\
\hline & & $0 \%$ & $0-10 \%$ & $11-50 \%$ & $51-100 \%$ & p Value \\
\hline \multirow[t]{2}{*}{ Central nervous system } & D & $46 \cdot 8$ & 0 & $49 \cdot 4$ & $3 \cdot 8$ & \\
\hline & C & $70 \cdot 0$ & 0 & $30 \cdot 0$ & 0 & $0.001^{\star}$ \\
\hline \multirow{2}{*}{ Peripheral nervous system } & D & 66.0 & $17 \cdot 9$ & $14 \cdot 7$ & $1 \cdot 3$ & \\
\hline & C & 83.0 & $14 \cdot 0$ & 3.0 & 0 & $0.006^{\star}$ \\
\hline \multirow[t]{2}{*}{ Autonomic nervous system } & D & 13.5 & $48 \cdot 7$ & $36 \cdot 5$ & $1 \cdot 3$ & \\
\hline & C & $26 \cdot 0$ & 53.0 & $21 \cdot 0$ & 0 & $0.009^{\star}$ \\
\hline
\end{tabular}

^Significant difference between divers and controls (Pearson's $\chi^{2}$ test).

$\mathrm{D}=$ Divers; $\mathrm{C}=$ controls 
The divers also had more symptoms from the ANS with orthostatic hypotension as the prevailing symptom. The orthostatic hypotension score was 23.7 for divers and $15 \cdot 7$ for controls $(p=0.003)$.

\section{ABNORMAL NEUROLOGICAL FINDINGS}

Table 4 records abnormal neurological findings for divers and controls. The same scoring system was used as for symptoms. The divers had significantly more abnormal findings from the cranial nerves than the controls. Five divers and none of the controls had anisocoria with difference more than $2 \mathrm{~mm}$. Two other divers and none of the controls had unilateral reduced vision from childhood, and one diver and one control had post-traumatic unilaterally reduced vision. One diver and one control had post-traumatic reduced field of vision in one eye, and another diver after one episode of DCS. Two divers but no controls had spontaneous horizontal nystagmus.

One diver and one control had reduced sensitivity in one infraorbital nerve. Six divers and three controls had abnormal findings from the acoustic nerve.

The divers had significantly more abnormal findings from the motor system. Postural hand tremor score was 14.7 for the divers and 6.0 for the controls $(p=0.042$, Fisher's exact two tailed test). The divers had significantly more abnormal findings from the sensory system. Reduced tactile sensitivity score in the right foot was $\mathbf{8 . 3}$ for the divers and 0 for the controls ( $p=0.002$, Fisher's exact two tailed test). Reduced tactile sensitivity score in the left foot was $7 \cdot 1$ for the divers and 0 for the controls ( $p$ $=0.008$, Fisher's exact two tailed test). Reduced algesia score in the right foot was 10.3 for the divers and 1.0 for the controls ( $p=0.003$, Fisher's exact two tailed test). Reduced algesia score in the left foot was 9.0 for the divers and 1.0 for the controls ( $p$ $=0.006$, Fisher's exact two tailed test). The divers had significantly more asymmetric or increased muscle stretch reflexes. The divers also had more asymmetric or absent abdominal reflexes.

In total 15 divers and one control had sensory or motor disturbances most commonly in the feet. These were compatible with an affected spinal cord or affected roots. One of these divers was severely affected (permanent central bladder paresis and sexual dysfunction). Two others were moderately affected (daily symptoms), and the rest of the cases were graded as mild.

Seven divers and one control had mild sensory peripheral polyneuropathy. The subjects with polyneuropathy drank no more alcohol than the others $(p=0 \cdot 4)$. One diver had paresis of the ulnar nerve and one paresis of the peroneal nerve.

\section{RISK FACTOR ANALYSIS}

Possible reasons for the neurological symptoms and findings by neurological examination were age, cerebral concussion, lumboischalgia, drinking alcohol, prevalence of DCS type 2, DCS types 1 and 2, air diving, saturation diving, and total diving. Data from all the 256 subjects were used in this analysis.

Table 5 gives the results from the risk factor analysis. Total diving, DCS 2 , and age were independently correlated with the neurological symptoms. Air diving, DCS 2, and age were independently correlated with the findings by neurological examination.

\section{SICK LEAVE DURING THE PAST THREE YEARS}

The divers had a mean of $2 \cdot 1$ (range $0-28$ ) weeks, and the controls a mean of $2 \cdot 8$ (range $0-48$ ) weeks sick leave. These were not statistically different $(p=0 \cdot 3)$.

Table 4 Abnormal neurological findings in divers and controls

\begin{tabular}{|c|c|c|c|c|c|c|}
\hline & & \multicolumn{5}{|c|}{ Abnormal neurological findings in per cent of variables } \\
\hline & & $0^{o}{ }_{o}$ & $0-10^{\circ}{ }_{o}$ & $11-50^{\circ}{ }_{o}$ & $51-100^{\circ}$ & p Value \\
\hline \multirow[t]{2}{*}{ Cranial nerves } & $\mathrm{D}$ & $85 \cdot 9$ & $12 \cdot 8$ & $1 \cdot 3$ & 0 & \\
\hline & C & $96 \cdot 0$ & 3.0 & $1 \cdot 0$ & 0 & $0.026^{\star}$ \\
\hline \multirow[t]{2}{*}{ Motor system } & $\mathrm{D}$ & $50 \cdot 6$ & $48 \cdot 7$ & 0.6 & 0 & \\
\hline & C & $67 \cdot 0$ & 33.0 & 0 & 0 & $0.030^{\star}$ \\
\hline \multirow[t]{2}{*}{ Sensory system } & $\mathrm{D}$ & 81.4 & $2 \cdot 6$ & $13 \cdot 5$ & $2 \cdot 6$ & \\
\hline & $\mathrm{C}$ & 94.0 & $4 \cdot 0$ & $2 \cdot 0$ & 0 & $0.005^{\star}$ \\
\hline \multirow[t]{2}{*}{$\mathrm{A} / \mathrm{IMR}$} & $\mathrm{D}$ & 76.9 & $19 \cdot 2$ & $3 \cdot 8$ & 0 & \\
\hline & $\mathrm{C}$ & $91 \cdot 0$ & $9 \cdot 0$ & 0 & 0 & $0.009 \star$ \\
\hline \multirow[t]{2}{*}{ APR } & D & 94.9 & 0 & $3 \cdot 2$ & 1.9 & \\
\hline & C & 98.0 & 0 & 1.0 & 1.0 & 0.436 \\
\hline \multirow[t]{2}{*}{ As/AbAR } & $\mathrm{D}$ & $79 \cdot 5$ & 0 & $8 \cdot 3$ & $12 \cdot 2$ & \\
\hline & C & $91 \cdot 0$ & 0 & $4 \cdot 0$ & $5 \cdot 0$ & $0 \cdot 049^{\star}$ \\
\hline
\end{tabular}

« Significant difference between divers and controls (Pearson's $\chi^{2}$ test).

$\mathrm{D}=$ Divers; $\mathrm{C}=$ controls.

$\mathrm{A} / \mathrm{IMR}=$ Asymmetric or increased muscle stretch reflexes.

$\mathrm{APR}=$ Asymmetric plantar reflexes.

As $/ \mathrm{AbAR}=$ Asymmetric or absent abdominal reflexes. 
Table 5 Risk factor analysis (stepwise multiple regression) for neurological signs and symptoms in divers and controls. Step 0 shows univariate relations between findings and risk factors. Last step shows independent correlations found

\begin{tabular}{|c|c|c|c|c|}
\hline & \multicolumn{2}{|l|}{ Step 0} & \multicolumn{2}{|c|}{ Last step } \\
\hline & $R$ & p Value & $R$ & p Value \\
\hline \multicolumn{5}{|c|}{ Neurological symptoms (NSY): } \\
\hline Total diving (ln) & $0 \cdot 326$ & $<0.0005$ & 0.326 & $<0.0005$ \\
\hline Air diving (ln) & 0.324 & $<0.0005$ & & \\
\hline $\operatorname{DCS} 1+2$ & 0.302 & $<0.0005$ & & \\
\hline DCS 2 & $0 \cdot 278$ & $<0.0005$ & $0 \cdot 193$ & $=0.0025$ \\
\hline Saturation diving $(\ln )$ & 0.251 & $<0.0005$ & & \\
\hline Age & 0.227 & $<0.0005$ & $0 \cdot 217$ & $<0.0005$ \\
\hline Lumboischialgia & $0 \cdot 170$ & $=0.0062$ & & \\
\hline Cerebral concussion & 0.067 & NS & & \\
\hline Alcohol & 0.016 & NS & & \\
\hline \multicolumn{5}{|c|}{ NSY $=-0.14+0.0027$ age $+0.0065 \ln$ (total diving) +0.0217 DCS 2} \\
\hline \multicolumn{5}{|c|}{ Neurological examination (NE): } \\
\hline Air diving (ln) & $0 \cdot 342$ & $<0.0005$ & 0.342 & $<0.0005$ \\
\hline Total diving (ln) & 0.338 & $<0.0005$ & & \\
\hline $\operatorname{DCS} 2$ & 0.305 & $<0.0005$ & $0 \cdot 221$ & $<0.0005$ \\
\hline $\operatorname{DCS} 1+2$ & 0.256 & $<0.0005$ & & \\
\hline Saturation diving $(\ln )$ & 0.231 & $<0.0005$ & & \\
\hline Age & $0 \cdot 189$ & $=0.0029$ & $0 \cdot 174$ & $=0.0051$ \\
\hline Lumboischialgia & 0.089 & NS & & \\
\hline Alcohol & 0.045 & NS & & \\
\hline Cerebral concussion & 0.003 & NS & & \\
\hline \multicolumn{5}{|c|}{$\mathrm{NE}=-0.0735+0.0129 \mathrm{DCS} 2+0.0037 \ln$ (air diving) +0.0011 age } \\
\hline
\end{tabular}

NSY = Symptoms from the CNS, PNS, and ANS.

ln = Natural logarithm of.

NS $=$ Non-significant correlation $(p>0 \cdot 1)$.

$\mathrm{R}=$ Correlation coefficient .

\section{Discussion}

The group of young commercial divers had significantly more subjective neurological symptoms and complaints, and more objective neurological findings than the age matched controls. In spite of this, all of them had a job. This situation is most probably due to their young age and its compensation for psychological and physical impairments. In this age group the results from natural ageing in the nervous system are minor. ${ }^{57}$

It can be claimed that the divers may be more aware of neurological symptoms than the controls because they have been taught about DCS and medical emergency in their training. The symptoms, however, were significantly correlated to total diving experience, prevalence of DCS, and age of the divers. The results cannot, therefore, be explained by a different knowledge of neurological symptoms. Other studies have reported that DCS and air diving may affect many parts of the nervous system. ${ }^{238910}$ Problems of concentration and short and long term memory occurred in approximately $21 \%$ of the divers. In the absence of depression such symptoms are presumably of organic origin. ${ }^{11}$ These results are supported by the results from neuropsychological studies. ${ }^{4}$ In spite of more neurological symptoms, the divers reported no more psychiatric disorders than the controls, which indicates that their mental health is not at risk.
The secondary response rate was $72 \%$ and we examined half of the Norwegian divers with a diving bell certificate. The inclusion criteria for the control group were few and divers and controls were accordingly incompatible in some respects. Because of the different education requirements between the groups the controls had more years of formal education than the divers. The divers, however, scored above average in IQ tests. ${ }^{4}$ The divers drank more alcohol than the controls, and alcohol was, therefore, applied as a risk factor because of its possible adverse effect on the nervous system. ${ }^{12}{ }^{13}$ It did not, however, seem to contribute significantly to the neurological signs and symptoms.

Twelve $(8 \%)$ of the divers had experienced disturbances of vision, vertigo, and reduced skin sensitivity (table 1) in non-diving situations, indicating that the influence on the nervous system during diving also continues after diving. The reason for this may be that deficits in neural perfusion during decompression persist after surfacing. ${ }^{10}$

Some divers had anisocoria, reduced field of vision, and spontaneous horizontal nystagmus. They had, however, no other neurological findings to identify a focal lesion. Participation of the ocular system has been reported in $\mathrm{DCS}^{14}$ and it is probable that the ocular findings of unknown cause are related to diving. The retinal capillary density in divers is lower than in control subjects. ${ }^{15}$ This could be caused 
either by intravascular bubble formation during decompression, or to altered behaviour of blood constituents and blood vessels.

Reduced algesia and tactile sense were found in the feet in $15^{\circ}$ o of the divers. They also had more asymmetric or increased muscle stretch reflexes, and more asymmetric or absent abdominal reflexes. In most cases the findings were compatible with an affected spinal cord or affected nerve roots. ${ }^{16}{ }^{17}$ Also, other divers had findings compatible with polyneuropathy, which may be caused by a direct effect of hyperbaric pressure ${ }^{1819}$ or from toxic agents. ${ }^{20}$

Seventy nine $\left(51^{\circ}{ }_{0}\right)$ of the divers had experienced DCS, a higher percentage than usually reported. For instance, in a group of commercial air divers $15 \%$ had had DCS, ${ }^{3}$ whereas only $2 \cdot 4^{\circ}$ of naval divers had DCS over a 12 year period. ${ }^{21}$ Established decompression procedures may not have been adhered to so rigorously in commercial divers, ${ }^{22}$ and DCS can also occur with use of standard decompression. ${ }^{23}$ According to data from The Norwegian Petroleum Directorate the incidence of DCS in the Norwegian sector of the North Sea decreased from 54 cases in 1978 to nine in 1989 , and there was a $40^{\circ}{ }_{0}$ increase in total saturation hours in the same period. Royal Norwegian Navy data from the land based treatment centres refer to an increase of DCS in commercial divers from eight cases in 1978 to 17 in 1988. Most of these were related to air surface supplied diving with surface decompression. There has been an increase in commercial land based diving during this period, but no registration has been performed. Also, there was an increase in treated sports divers from eleven to 40 . The data indicate that there has been an improvement in diving procedures over the past years in North Sea diving but DCS is still a problem.

The analysis of risk factors showed that total prevalence of DCS, and not only DCS 2, was significantly correlated with symptoms and neurological findings in these divers. DCS may lead to permanent, although in most cases, mild neurological dysfunction. The results indicate that DCS symptoms should be treated immediately. Treatment tables with long bottom time and slow decompression should be used to prevent recurrence of symptoms, ${ }^{24}$ as the prognosis may otherwise be dubious. $^{2}$

Total exposure to diving was also significantly correlated with neurological signs and symptoms. Both Rozsahegyi ${ }^{8}$ and Dolmierski et al ${ }^{3}$ found that some caisson workers and air divers who did not have a history of DCS also had neurological problems. We do not know the risk factors which may be hidden within "total exposure to diving." Subclinical episodes of DCS may be one, as the nervous system may be injured with only very slight or no symptoms. ${ }^{17}$

Oxygen and hyperbaric pressure are probably other risk factors. It is customary in saturation diving to use 0.4 bar oxygen during bottom time and 0.5 or 0.6 bar during decompression. Raised oxygen pressure is toxic to the nervous system. ${ }^{25}{ }^{26}$ We do not know, however, whether these oxygen concentrations may be harmful. Saturation divers live with moderately raised oxygen pressures for many days at a time. Some complain about lung symptoms, fatigue, and joint pains that they attribute to the oxygen pressure. Furthermore, it has never been documented that increased oxygen pressure decreases the incidence of DCS. ${ }^{27}$ Raised oxygen pressure is, therefore, presumably unwarranted. In this study oxygen could not be evaluated as a risk factor since it is not possible in a retrospective study to establish the oxygen content in all previous dives. Prospective studies are therefore needed.

The conclusion from this study is that the divers had more symptoms and abnormal neurological findings from the nervous system than the controls. These findings were significantly correlated with exposure to air and saturation diving and the prevalence of DCS. Care should be taken to treat even mild symptoms immediately and better decompression tables should be produced. There is also a need for better knowledge of DCS in the diving community.

We are indebted to Statoil, Norsk Hydro, and the Royal Norwegian Council for Scientific and Industrial Research who are financing the national research programme on long term health effects of diving. We are also indebted to the participating divers and controls, to Svein Eidsvik MD, Royal Norwegian Navy, to The Norwegian Petroleum Directorate, and to the staff of the Norwegian Underwater Technology Centre for their collaboration in this investigation.

Requests for reprints to: Kari Todnem, NUTEC, PO Box 6, N-5034 Ytre Laksevåg, Norway.

1 Elliott DH, Kindwall EP. Manifestations of the decompression disorders. In: Bennet PB, Elliott DH, eds. The physiology and medicine of diving. London: Bailliere Tindall, 1982:461-72.

2 Rozsahegyi I. Late consequences of the neurological forms of decompression sickness. Br J Ind Med 1959;16:311-7.

3 Dolmierski R, Kwiatkowski SR, Nitka J, Palubicki J, Laba L. Neurological, psychiatric and psychological examination of divers in the light of their professional work. Bull Inst Marit Trop Med Gdynia 1981;32:141-52.

4 Værnes RJ, Klove H, Ellertsen B. Neuropsychologic effects of saturation diving. Undersea Biomed Res 1989;16:233-51.

5 Skre H. Neurological signs in a normal population. Acta Neurol Scand 1972;48:575-606.

6 Dixon WJ, Brown MB, Engelman L, et al. BMDP Statistical Software. California: University of California Press 1985: 251-63.

7 Jenkyn LR, Reeves AG, Warren T, et al. Neurologic signs in senescence. Arch Neurol 1985;42:1154-7.

8 Rozsahegyi I, Roth B. Participation of the central nervous system in decompression. Industrial Medicine and Surgery 1966;35:101-10.

9 Peters BH, Levin HS, Kelly PJ. Neurologic and psychologic 
manifestations of decompression illness in divers. Neurology 1977;27:125-7.

10 Adkisson GH, Hodgson M, Smith F, et al. Cerebral perfusion deficits in dysbaric illness. Lancet 1989;2(8655):119-22.

11 Brodal A. Neurological anatomy in relation to clinical medicine. New York: Oxford University Press, 1981:673-89.

12 Victor M, Adams RD, Mancall EL. A restricted form of cerebellar cortical degeneration occurring in alcoholic patients. Arch Neurol 1959;1:579-688.

13 Kemppainen R, Juntunen J, Hillbom M. Drinking habits and peripheral alcoholic neuropathy. Acta Neurol Scand 1982; 65:11-8.

14 Ostachowicz MZ. History of the ophthalmological investigations in decompression sickness. Bull Inst Marit Trop Med Gdynia 1987;38:207-9.

15 Polkinghorne PJ, Sehmi K, Cross MR, Minassian D, Bird AC. Ocular fundus lesions in divers. Lancet 1988;2(8625):1381-3.

16 Palmer AC, Calder IM, McCallum RI, Mastaglia FL. Spinal cord degeneration in a case of "recovered" spinal decompression sickness. Br Med J 1981;283:888.

17 Palmer AC, Calder IM, Hughes JT. Spinal cord degeneration in divers. Lancit 1987; i: 1365-6.

18 Grossman Y, Kendig JJ. Pressure and temperature modulation of conduction in a bifurcating axon. Undersea Biomed Res 1986;13:45-61.

19 Todnem K, Knudsen G, Riise T, Nyland H, Aarli JA. Nerve conduction velocity in man during deep diving to $360 \mathrm{msw}$ : Undersea Biomed Res 1989;16:31-40.

20 Dyck PJ, Low PA, Stevens JC. Diseases of peripheral nerves. In: Baker AB, Baker LH, eds. Clinical neurology. Philadelphia: Harper \& Row 1983;4(51):58-99.

21 Hoiberg A. Consequences of U.S. Navy diving mishaps: decompression sickness. Undersea Biomed Res 1986;13: 383-93.

22 Dounis A, Mitropoulos D. Urinary problems in decompression sickness. Paraplegia 1985;23:20-5.

23 Hughes JS, Eckenhoff RG. Spinal cord decompression sickness after standard U.S. Navy air decompression. Military Medicine 1986;151:166-8.

24 Lee HC, Niu KC, Chen SH, Chang LP, Cho SH. Therapeutic effect on type 2 decompression sickness. Journal of Hyperbaric Medicine 1988;3:235-42.

25 Donald KW. Oxygen poisoning in man. $1 \& 2 . \mathrm{Br}$ Med $J$ 1947;1:667-72, 712-7.

26 Clark JM. Oxygen toxicity. In: Bennet PB, Elliott DH, eds. The physiology and medicine of diving. London: Bailliere Tindall, 1982:200-38.

27 Weathersby PK, Hart BL, Flynn ET, Walker WF. Role of oxygen in the production of human decompression sickness. $J$ Appl Physiol 1987;63:2380-7.

Accepted 3 April 1990 